\title{
Article
}

\section{Head Positioning in Acute Stroke [Correspondence]}

Anderson, Craig, Robinson, Tony and Watkins, Caroline Leigh

Available at http://clok.uclan.ac.uk/20057/

Anderson, Craig, Robinson, Tony and Watkins, Caroline Leigh ORCID: 00000002-9403-3772 (2017) Head Positioning in Acute Stroke [Correspondence]. The New England Journal of Medicine, 377 (11). pp. 1102-3. ISSN 0028-4793

It is advisable to refer to the publisher's version if you intend to cite from the work. http://dx.doi.org/10.1056/NEJMc1709517

For more information about UCLan's research in this area go to

http://www.uclan.ac.uk/researchgroups/ and search for < name of research Group>.

For information about Research generally at UCLan please go to http://www.uclan.ac.uk/research/

All outputs in CLoK are protected by Intellectual Property Rights law, including Copyright law. Copyright, IPR and Moral Rights for the works on this site are retained by the individual authors and/or other copyright owners. Terms and conditions for use of this material are defined in the policies page.

\section{CLoK}

Central Lancashire online Knowledge www.clok.uclan.ac.uk

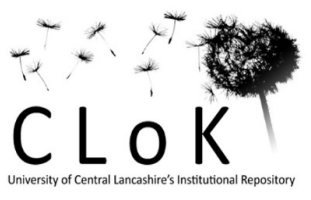


Supported by grants from the Congressionally Directed Medical Research Program, Autism Research Program (AR130253, to Drs. Glickman and Dobkins), and the Eunice Kennedy Shriver National Institute of Child Health and Human Development of the National Institutes of Health (R01 HD052804-01A2, to Dr. Dobkins).

Disclosure forms provided by the authors are available with the full text of this letter at NEJM.org.

1. Ozonoff S, Young GS, Carter A, et al. Recurrence risk for autism spectrum disorders: a Baby Siblings Research Consortium study. Pediatrics 2011;128(3):e488-95.

2. Penn AH, Carver LJ, Herbert CA, et al. Breast milk protects against gastrointestinal symptoms in infants at high risk for autism during early development. J Pediatr Gastroenterol Nutr 2016;62:317-27.

3. Jain A, Marshall J, Buikema A, Bancroft T, Kelly JP, Newschaffer CJ. Autism occurrence by MMR vaccine status among US children with older siblings with and without autism. JAMA 2015;313:1534-40.

4. Kuwaik G, Roberts W, Brian J, et al. Immunization uptake in siblings of children with autism. Pediatrics 2008;122:684-5.

5. Taylor LE, Swerdfeger AL, Eslick GD. Vaccines are not associated with autism: an evidence-based meta-analysis of casecontrol and cohort studies. Vaccine 2014;32:3623-9.

DOI: $10.1056 /$ NEJMc1708223

\section{Head Positioning in Acute Stroke}

TO THE EDITOR: Anderson et al. (June 22 issue) ${ }^{1}$ report that head positioning did not influence outcome in patients with acute stroke. The lyingflat position theoretically increases cerebral perfusion, which may alleviate acute ischemia through the recruitment of collaterals. ${ }^{2}$ However, in the Head Positioning in Acute Stroke Trial (HeadPoST), reported by Anderson et al., many patients had conditions that presumably were not the result of large perfusion defects: specifically, there were patients with stroke mimics ( $4.9 \%)$, lacunar stroke $(30.2 \%)$, or intracerebral hemorrhage $(8.4 \%)$. Moreover, the low median scores on the National Institutes of Health Stroke Scale in both study groups ${ }^{1}$ suggest that few patients had proximal occlusions of the intracranial arteries, which implies that many patients did not require improvement in their collateral cerebrovascular network during acute stroke. The absence of large ischemic stroke has been proposed as a possible reason for the failure of endovascular therapy to show clinical benefit in some recent trials. ${ }^{3,4}$ Head positioning therefore might be evaluated in a more selective population, such as patients with large strokes or large ischemic areas at risk, ${ }^{5}$ before we give up on this nonpharmacologic strategy. Igor Sibon, M.D., Ph.D.

$\mathrm{CHU}$ de Bordeaux

Bordeaux, France

Patrick Gérardin, M.D., Ph.D.

Alexandre Gauthier, M.D.

$\mathrm{CHU}$ de La Réunion

Saint Pierre, France

agauth05@gmail.com

No potential conflict of interest relevant to this letter was reported.
1. Anderson CS, Arima H, Lavados P, et al. Cluster-randomized, crossover trial of head positioning in acute stroke. N Engl J Med 2017;376:2437-47.

2. Beretta S, Versace A, Carone D, et al. Cerebral collateral therapeutics in acute ischemic stroke: a randomized preclinical trial of four modulation strategies. J Cereb Blood Flow Metab 2017 January 1 (Epub ahead of print).

3. Kaijser M, Andersson T. Endovascular treatment for acute ischemic stroke. N Engl J Med 2013;368:2430.

4. Arnold M, Schroth G, Gralla J. Endovascular treatment for acute ischemic stroke. N Engl J Med 2013;368:2431.

5. Kerry SM, Cappuccio FP, Emmett L, Plange-Rhule J, Eastwood JB. Reducing selection bias in a cluster randomized trial in West African villages. Clin Trials 2005;2:125-9.

DOI: 10.1056/NEJMc1709517

TO THE EDITOR: We write to request clarification of the consent process used in HeadPoST, in which hospital executives provided institutional consent to implement an intervention and patients provided individual consent only for postintervention data collection and follow-up. Although cluster-randomized trials that expose groups to a common intervention (e.g., community water sanitation) often preclude prospective individual consent, the bed-position intervention in HeadPoST addressed individual patients (which makes it an "individual-cluster" trial). ${ }^{1}$ Time constraints ${ }^{2}$ seemingly did not preclude consent: interventions were initiated a median of 7 hours after hospital arrival and continued for 24 hours. The investigators describe the study as having "minimal risk," which is generally defined as risk that is similar to the risks involved in daily life (and is distinct from equipoise). ${ }^{3}$ But HeadPoST was directed at brain perfusion in acute stroke and was designed to detect effects on disability at 90 days. A final 
rationale the authors provided for cluster consent is the avoidance of response bias, but this rationale could conceivably apply to the forgoing of consent in any clinical trial. Thus, it remains unclear to us that sufficient justification has been provided for bypassing the step of obtaining individual consent from participants.

William B. Feldman, M.D., D.Phil.

Brigham and Women's Hospital

Boston, MA

Winston Chiong, M.D., Ph.D.

University of California, San Francisco

San Francisco, CA

winston.chiong@ucsf.edu

Scott Y.H. Kim, M.D., Ph.D.

National Institutes of Health

Bethesda, MD

No potential conflict of interest relevant to this letter was reported.

1. McRae AD, Weijer C, Binik A, et al. When is informed consent required in cluster randomized trials in health research? Trials 2011;12:202.

2. Feldman WB, Kim AS, Josephson SA, Lowenstein DH, Chiong W. Effect of waivers of consent on recruitment in acute stroke trials: A systematic review. Neurology 2016;86:1543-51.

3. International ethical guidelines for health-related research involving humans. Geneva: Council for International Organizations of Medical Sciences, World Health Organization, 2016 (https://cioms.ch/wp-content/uploads/2017/01/WEB-CIOMS -EthicalGuidelines.pdf).

DOI: 10.1056/NEJMc1709517

TO THE EDITOR: In their evaluation of head positioning after acute stroke, Anderson et al. reported disability outcome and safety to be similar whether patients were maintained in a flat position or allowed to sit up, with a head elevation of 30 degrees, during the first 24 hours after stroke. The median time from stroke onset to out-of-bed activity and rehabilitation was 38 hours in the group that was lying flat. In the Efficacy and Safety of Very Early Mobilization within 24 Hours of Stroke Onset (AVERT) study, usual care included mobilization within the first 24 hours after stroke for most patients. ${ }^{1}$ Moreover, shorter and more frequent mobilization soon after acute stroke has been shown to improve outcomes at 3 months. ${ }^{2}$ The effect of restricting out-of-bed activity on outcomes for disability after an acute stroke is interesting, especially when considered in light of the reduced adherence to the practice of maintaining patients in a flat-lying position as opposed to a sitting-up position in the study by Anderson et al. (Table S5 in the Supplementary Appendix, available with the full text of the article at NEJM .org). It would be interesting to examine the effect of discontinuation of the flat-lying position soon after stroke in an additional strict, per-protocol analysis.

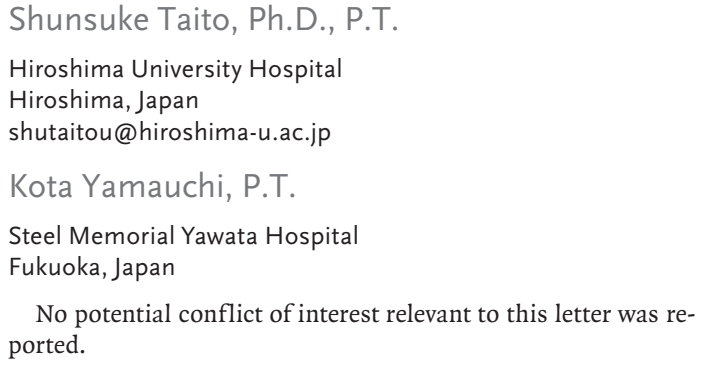

No potential conflict of interest relevant to this letter was reported.

1. AVERT Trial Collaboration Group. Efficacy and safety of very early mobilisation within $24 \mathrm{~h}$ of stroke onset (AVERT): a randomised controlled trial. Lancet 2015;386:46-55.

2. Bernhardt J, Churilov L, Ellery F, et al. Prespecified dose-response analysis for A Very Early Rehabilitation Trial (AVERT). Neurology 2016;86:2138-45.

DOI: 10.1056/NEJMc1709517

THE AUTHORS REPLY: Sibon et al. raise an appropriate question in regard to the potential benefits of lying flat after stroke in a highly selected group of patients - those with a large ischemic penumbra resulting from the proximal occlusion of a large vessel. We chose a study design that would allow for an efficient evaluation of a plausible, modest treatment effect in a large but carefully defined and broad group of patients with stroke. The lack of statistical heterogeneity across several predefined subgroups - including pathologic ischemic subtype - provides some reassurance regarding the consistency of a neutral effect on outcome. The well-balanced baseline characteristics of the participants indicate that our central method of randomization was robust.

We agree with Feldman et al. that informed consent remains the appropriate standard for the evaluation of interventions with uncertain or known benefits and harms. However, opt-out consent is increasingly being used for noninterventional registry studies to maximize participation and thus the external validity of the accumulated "real-world" data. ${ }^{1}$ We believe that our decision to obtain consent by means of the cluster-guardian format was necessary, and this format was endorsed by the ethics committees at 114 hospitals in nine countries for several reasons: to minimize recruitment and selection bias; to 
facilitate rapid implementation of the intervention in large numbers of patients by the clinical staff at different institutions, all in the chaos of emergency departments; and to avoid potential responder bias in the outcome assessments of patients (or surrogates) who may have thought they had received "nonstandard" care. Our decision to view the matter of head position as involving "low risk" was based on several considerations: the insufficient amount of level 1 evidence specifying the benefits and harms of head positioning for patients with acute stroke; the fact that people change their head position within the ranges being tested during routine hospital care and in daily life, as they shift from activity during the day to rest and sleep at night; and the view that patient care would not be compromised by either of the interventions.

Finally, Taito and Yamauchi raise an important point regarding an unresolved issue that should be addressed in another trial - that of the appropriate timing (and intensity) of early mobilization after acute stroke that follows from the unexpected results of the AVERT trial. ${ }^{2}$ Unfortunately, we did not collect data on the specific time that patients began to move outside the confines of the bed.

Craig S. Anderson, Ph.D.

University of New South Wales

Sydney, NSW, Australia

canderson@georgeinstitute.org.cn

Tom Robinson, M.D.

University of Leicester

Leicester, United Kingdom

Caroline Watkins, Ph.D.

University of Central Lancashire

Preston, United Kingdom

Since publication of their article, the authors report no further potential conflict of interest.

1. National statement on ethical conduct in human research (2007) — updated May 2015. Canberra, ACT: National Health and Medical Research Council, Australian Research Council and Australian Vice-Chancellors Committee, Commonwealth of Australia (https://www.nhmrc.gov.au/guidelines/publications/e72).

2. AVERT Trial Collaboration Group. Efficacy and safety of very early mobilisation within $24 \mathrm{~h}$ of stroke onset (AVERT): a randomised controlled trial. Lancet 2015;386:46-55.

DOI: 10.1056/NEJMc1709517

\section{Transplanting HCV-Infected Kidneys into Uninfected Recipients}

TO THE EDITOR: Goldberg et al. (June 15 issue) ${ }^{1}$ report cure of hepatitis $\mathrm{C}$ virus (HCV) infection, after transplantation of kidneys infected with HCV (genotype 1) into HCV-negative recipients, with the use of a 12-week course of elbasvirgrazoprevir. However, data on other types of solid-organ transplantation are lacking. Here, we report cure of HCV infection after accidental transmission of HCV from one organ donor to five different recipients (Table 1). The 55-year-old female donor did not belong to a group considered to be at high risk for HCV infection, and routine testing for anti-HCV IgG was negative. However, retrospective analysis revealed lowlevel HCV RNA (genotype 1a) viremia. All the transplant recipients were $\mathrm{HCV}$-negative before transplantation and had development of $\mathrm{HCV}$ viremia in the early post-transplantation period. A 12-week course of different sofosbuvir-based anti-HCV regimens ${ }^{2-4}$ was used to treat four of the patients. The liver-transplant recipient died from septic shock early after transplantation, before treatment could have been initiated. All four recipients who received treatment currently have stable graft function and cure of HCV infection (sustained virologic response at week 12 after treatment).

In summary, we contribute further evidence that the early initiation of a sofosbuvir-based regimen is an efficient and safe treatment option in the context of different types of solidorgan transplantation from an HCV-positive donor to an HCV-negative recipient.

Fabian Halleck, M.D

Klemens Budde, M.D.

Michael Duerr, M.D.

Charité-Universitätsmedizin Berlin

Berlin, Germany

fabian.halleck@charite.de

\section{and Others}

A complete list of authors is available with the full text of this letter at NEJM.org.

No potential conflict of interest relevant to this letter was reported.

1. Goldberg DS, Abt PL, Blumberg EA, et al. Trial of transplantation of HCV-infected kidneys into uninfected recipients. N Engl J Med 2017;376:2394-5. 